Check for updates

London

Cite this as: BMJ 2020;370:m3271

http://dx.doi.org/10.1136/bmj.m3271

Published: 19 August 2020

\section{Covid-19: Care homes in Belgium and Spain had "alarming living conditions," says MSF report}

\author{
Jacqui Thornton
}

A report into the global response to coronavirus outbreaks has heavily criticised the "alarming living conditions" in Belgian and Spanish care homes, the former being described as a "true humanitarian crisis."

The report, ${ }^{1}$ by Médecins Sans Frontières (MSF), documents the first phase of the non-governmental organisation's global covid-19 response from March until May. During that time it committed "substantial resources" both to developing dedicated covid-19 projects and to maintaining essential healthcare in its existing programmes worldwide, including interventions in Italy, Spain, Belgium, and France.

Operations in the four European countries included projects supporting retirement and nursing homes, hospitals, and primary healthcare facilities, as well as providing protection and care to vulnerable groups in reception facilities, refugee camps, homeless shelters, and prisons. Smaller projects were set up in Portugal, the UK, and Switzerland.

But it was Belgium and Spain where the living conditions-as well as the lack of protective equipment and sufficient personnel and the enormous emotional burden on caregivers in care homes-caused high concern. This led MSF to alert national authorities on "several occasions."

\section{"Drastic deterioration"}

In Belgium, MSF shifted its activities from hospitals to long term care facilities in early April. Nine mobile teams, each with a nurse and health promoter, visited 174 care homes.

The teams assessed local facilities and preparedness measures, often identifying a lack of knowledge of basic hygiene rules and safety and treatment protocols, as well as shortages of staff and protective equipment, the report found.

Stephanie Goublomme, a Belgian MSF project coordinator, said, "Retirement homes were asked to operate like hospitals, but not given the protective means and necessary personnel to do so. We witnessed a true humanitarian crisis."

The report was just as damning in its description of the Spanish response, blaming "little outbreak preparedness, a lack of epidemiological surveillance, inadequate infection prevention and control, missing resources for primary and palliative care, and an increased workload for staff." As a result there was a "drastic deterioration of the health situation among residents of many Spanish nursing homes," the report said.

MSF supported 543 retirement and care homes and thousands of health professionals and caregivers in Spain, with tailored face-to-face and remote training.

Ximena di Lollo, MSF care home coordinator for Spain and Portugal, said, “As a society, we will need to have a good think about why the priority in this pandemic has been hospitals and other medical facilities, and why barely a thought has been given to the most vulnerable."

\section{Preparedness}

In early April, MSF issued an urgent call to Spanish health authorities to allocate additional resources and ensure that care for elderly patients was appropriate and compassionate, allowing for dignified farewells with families.

In Belgium, after developing tailored recommendations for each facility, MSF returned to the retirement homes with infection prevention and control recommendations and to conduct staff training.

The outreach visits gave caregivers a much needed opportunity to voice their distress and grief after weeks of working in strict confinement, with fears of getting infected and sadness about residents who lost their lives away from loved ones. MSF is now working with Belgian health authorities to improve preparedness and response plans and to create better support networks for caregivers.

In Europe overall from March to May, MSF teams in Europe directly supported 795 retirement communities, nursing homes, and long term care facilities, as well as running more than 250 health promotion and training sessions. In June and July MSF published extensive recommendations and advocated for improving preparedness, response measures, and overall care in retirement homes in Belgium and Spain.

The report did not cover nursing homes in the UK. But MSF reported that it had worked in the UK for the first time from mid-April, partnering with University College Hospital on the Homeless Sector Plan to care for London's homeless population by converting a hotel to a covid-19 care facility, managing 40 beds and holding 60 patient consultations. 
The report is the first in a series of accountability reports and operational snapshots of MSF's global covid-19 response. The second is scheduled for publication in October and will cover activities from June to August. A third report will be released in early 2021.

1 Médecins Sans Frontières. Responding to covid-19 global accountability report 1: March to May 2020. Aug 2020. https://politi.co/2E67mQE.

This article is made freely available for use in accordance with BMJ's website terms and conditions for the duration of the covid-19 pandemic or until otherwise determined by BMJ. You may use, download and print the article for any lawful, non-commercial purpose (including text and data mining) provided that all copyright notices and trade marks are retained. 